\title{
Increased sensitivity to TRAlL-induced apoptosis occurs during the adenoma to carcinoma transition of colorectal carcinogenesis
}

\author{
A Hague', DJ Hicks ${ }^{2}$, F Hasan ${ }^{2}$, H Smartt ${ }^{2}$, GM Cohen ${ }^{3}$, C Paraskeva ${ }^{*, 2}$ and M MacFarlane ${ }^{3}$ \\ 'Department of Oral and Dental Science, University of Bristol, Lower Maudlin Street, Bristol BSI 2LY, UK; '2 Cancer Research Campaign Colorectal Tumour \\ Biology Research Group, Department of Pathology and Microbiology, University of Bristol School of Medical Sciences, University Walk, Bristol BS8 ITD, \\ UK; ${ }^{3}$ MRC Toxicology Unit, Hodgkin Building, University of Leicester, PO Box 138, Leicester Road, Leicester LEI 9HN, UK
}

The death ligand TRAIL (Apo2L) has potential for cancer therapy, since tumour cells are thought to be more sensitive than normal cells. We investigated whether sensitivity to TRAIL increases during the adenoma to carcinoma transition of colorectal carcinogenesis. Under the same culture conditions, we compared the extent of TRAIL-induced apoptosis in four premalignant adenoma and three carcinoma cell lines. Although TRAIL induced some apoptosis in adenoma cultures, the carcinoma cell lines were significantly more sensitive $(P<0.00 \mathrm{I})$. This finding was recapitulated in an in vitro model of tumour progression in which conversion of the adenoma cell line $A A / C I$ to a tumorigenic phenotype was associated with increased TRAIL sensitivity $(P<0.00 I)$. Increased TRAIL sensitivity during colorectal carcinogenesis has been previously attributed to changes in the balance between TRAIL receptors TRAIL-RI and -R2 and 'decoy' receptors TRAIL-R3 and -R4 during malignant progression. To address this, cell surface receptor expression was measured by flow cytometry. In summary, during colorectal carcinogenesis, there is a marked increase in sensitivity to TRAIL-induced apoptosis associated with progression from benign to malignant tumour that could be exploited for colon cancer therapy, but alterations in cell surface TRAIL receptor expression may not be the primary reason for this change.

British Journal of Cancer (2005) 92, 736-742. doi:I0.1038/sj.bjc.6602387 www.bjcancer.com

Published online I February 2005

(c) 2005 Cancer Research UK

Keywords: TRAIL; colon; adenoma; carcinoma; apoptosis

Tumour necrosis factor-related apoptosis-inducing ligand (TRAIL/ Apo2L) mediates rapid apoptosis in cancer cell lines of varied tissue origin (Wiley et al, 1995; Pitti et al, 1996) and has generated much interest as a potential therapeutic agent due to its apparent differential effects on normal and tumour cells (Wang and ElDeiry, 2003). Tumour necrosis factor-related apoptosis-inducing ligand interacts with four different membrane-bound receptors, two with cytoplasmic death domains, TRAIL-R1 (DR4) and TRAIL-R2 (DR5), and two so-called 'decoy receptors' TRAIL-R3 (DcR1) and TRAIL-R4 (DcR2) (Ashkenazi and Dixit, 1998). When TRAIL binds the receptors $\mathrm{R} 1$ and $\mathrm{R} 2$, the death signal is transmitted through their intracellular protein - protein interacting death domains via cytoplasmic adaptor molecules resulting in an early activation of caspase-8 (Griffith et al, 1998; MacFarlane et al, 2000a). The activation of the caspase cascade leads, in turn, to cleavage of intracellular substrates such as poly-(ADP-ribose) polymerase (PARP) (Lazebnik et al, 1994). However, the death receptors can also transmit signals for cell survival through NF- $\kappa \mathrm{B}$, and via caspase- 8 can activate JNK and p38 MAP kinase pathways (Chaudhary et al, 1997; Schneider et al, 1997; Mühlenbeck et al, 1998; MacFarlane et al, 2000b). TRAIL-R3 and TRAIL-R4 are unable to transmit the death signal, since TRAIL-R3 does not have

* Correspondence: Professor C Paraskeva;

E-mail: c.paraskeva@bristol.ac.uk

Received 17 August 2004; revised 25 November 2004; accepted 8 December 2004; published online I February 2005 a death domain and TRAIL-R4 has a death domain that is substantially deleted (French and Tschopp, 1999). However, in some situations, TRAIL-R4 retains the ability to activate the NF- $\kappa \mathrm{B}$ pathway (Degli-Eposti et al, 1997). Initially, the differential sensitivity between normal and cancer cells was thought to be due to the presence of decoy receptors on normal cells (Ashkenazi and Dixit, 1998; Green, 1998). More recent studies have failed to find an obvious correlation between decoy receptor expression and the apoptotic response to TRAIL, with levels of TRAIL-R1 and the caspase- 8 inhibitory protein c-FLIP being more likely to affect the sensitivity of some cells to TRAIL-induced apoptosis (Kim et al, 2000).

Colorectal cancer cells have been reported to be sensitive to TRAIL-induced death (Gliniak and Le, 1999; Lacour et al, 2001; Lee et al, 2001; Ravi et al, 2001). The potential of TRAIL for colorectal cancer treatment is highlighted by the ability of TRAIL to inhibit growth of xenografts of several colon carcinoma cell lines in mouse models and to cooperate with chemotherapeutic agents such as 5-fluorouracil (5-FU), cisplatin, doxorubicin and camptothecin analogue CPT-11 (Ashkenazi et al, 1999; Gliniak and Le, 1999; Lacour et al, 2001, 2003; Shimoyama et al, 2002). In the carcinoma cell line HT29, chemotherapeutic agents, as well as potentiating the mitochondrial amplification of the caspase cascade, enhance recruitment of the adapter protein FADD and caspase- 8 to the death-inducing signal complex (DISC) (Lacour et al, 2003).

Although Sheikh et al (1999) reported overexpression of the decoy receptor TRAIL-R3 mRNA in four out of six colon cancers, with TRAIL-R3 overexpression conferring relative TRAIL 
resistance, Koornstra et al (2003) found no significant alterations in expression of the decoy receptors in colonic tumours compared to normal colonic epithelium in vivo. Although loss of heterozygosity of TRAIL-R2 has been observed in approximately half of colorectal carcinomas, mutations of the two TRAIL receptor genes are rare (Arai et al, 1998). The loss of heterozygosity for TRAIL-R2 is not reflected in the level of protein in the tumours (Koornstra et al, 2001), and TRAIL-R1 and TRAIL-R2 proteins are overexpressed in colonic tumours relative to normal colonic mucosa (Koornstra et al, 2003). However, in colorectal carcinomas, expression of TRAIL-R1, but not TRAIL-R2, correlates with disease-free survival (Sträter et al, 2002a).

Normal colonocytes cultured as intact crypts embedded in collagen have previously been reported to be relatively resistant to TRAIL-induced apoptosis compared to colorectal carcinoma cells (Sträter et al, 2002b), but it is not known whether the sensitivity to TRAIL is acquired early or late in colorectal carcinogenesis, since the response of premalignant adenoma cells to TRAIL has never been examined. Koornstra et al (2003) showed that, in vivo, cytoplasmic TRAIL-R1 and -R2 expression was higher in both adenomas and carcinomas compared to normal colonic epithelium; however, there were no further changes in expression of either TRAIL receptors or decoy receptors between adenomas and carcinomas. From these results, it might be assumed that the sensitivity to TRAIL is acquired early in colorectal tumorigenesis during the formation of the adenoma, and that this is due to the changes in TRAIL receptor expression. However, the cell surface expression of TRAIL receptors in adenoma cells has not been examined, and this could have an important bearing on the relative TRAIL sensitivity of colorectal epithelial cells during tumour progression. In this study, we addressed whether TRAIL sensitivity increases in association with the adenoma to carcinoma transition by comparing the response of four adenoma cell lines and three carcinoma cell lines to TRAIL under the same culture conditions. This is important because Larribere et al (2004) have shown that the response to TRAIL is dependent on culture conditions and that growth factor signalling through phosphatidyl-inositol-3 kinase and its downstream target, Akt, attenuates TRAIL-induced apoptosis of normal human melanocytes. In addition, we used a model of tumour progression in which an adenoma cell line had been transformed to a malignant phenotype in vitro (Williams et al, 1990); this allowed us to measure directly whether TRAIL sensitivity increased with acquisition of malignancy, again under the same culture conditions. To assess whether the relative abundance of TRAIL receptors on the cell surface accounted for differences in sensitivity to TRAIL-induced apoptosis, we measured cell surface expression of TRAIL-R1, -R2, -R3 and -R4 by flow cytometry.

\section{MATERIALS AND METHODS}

\section{Cell lines and culture conditions}

The adenoma cell lines used were AA/C1, RG/C2, AN/C1 and RR/ $\mathrm{C} 1$. These cells were capable of growth after trypsinisation to single cells and are derivatives of the cell lines PC/AA (Paraskeva et al, 1984), S/RG (Paraskeva et al, 1989), S/AN (Paraskeva et al, 1989) and S/RR (Williams et al, 1992). The carcinoma cell lines used were HT29 (Fogh and Trempe, 1975), SW620, derived from a lymph node metastasis (Leibovitz et al, 1976), and KS (Hague et al, 1997), which was derived in our laboratory using the same techniques as for the adenoma cultures. Whereas the four adenoma cell lines were anchorage-dependent and did not form tumours in nude mice (Williams et al, 1990; Hague et al, 1997), the carcinoma cell lines were anchorage-independent and tumorigenic after subcutaneous injection in nude mice. The AA/C1/SB/10 cell line is an in vitro-transformed variant of the AA/C1 adenoma cell line that is anchorage-independent and forms tumours in nude mice (Williams et al, 1990).

All of the cell lines used in this study were grown in Dulbecco's modified Eagle's medium (DMEM) (Gibco) containing 20\% fetal bovine serum (Gibco, batch selected), glutamine $(2 \mathrm{mM})$, insulin $\left(0.2 \mathrm{u} \mathrm{ml}^{-1}\right)$, hydrocortisone sodium succinate $\left(1 \mu \mathrm{g} \mathrm{ml}^{-1}\right)$, penicillin $\left(100 \mathrm{u} \mathrm{ml}^{-1}\right)$ and streptomycin $\left(100 \mu \mathrm{g} \mathrm{ml}^{-1}\right)$. Cells were grown in T25 flasks and were routinely passaged using trypsin (0.1\%) (Difco, West Molesey, Surrey, UK)/EDTA $(0.1 \%)$ (AnalaR, BDH).

\section{Preparation of TRAIL and treatment of cells}

The TRAIL preparation used was recombinant soluble TRAIL with $\mathrm{N}$-terminal T7 and $\mathrm{His}_{6}$ tags obtained by nickel affinity purification as previously described (MacFarlane et al, 1997). For doseresponse experiments, a stock solution of TRAIL $\left(1 \mathrm{mg} \mathrm{ml}^{-1}\right)$ was prepared in EDTA $(150 \mathrm{~mm})$ and diluted in medium to give final concentrations of $0.25,0.5$ and $1.0 \mu \mathrm{g} \mathrm{ml}^{-1}$. Duplicate or triplicate flasks were treated with each TRAIL concentration or EDTA only. Control cultures were treated with the vehicle only.

\section{Identification of apoptosis}

As previously demonstrated in these cells (Hague et al, 1993), apoptosis results in rapid detachment from the flask and the apoptotic cells float in the medium. Floating cells were collected at the end of the treatment time and adherent cells were harvested by trypsinisation. Adherent and floating cells were quantified using a counting chamber. The extent of apoptotic cell shedding was calculated as the number of floating cells per flask divided by the total cell yield (number of adherent plus floating cells). Adherent and floating cells were examined separately for apoptotic morphology by acridine orange staining as described previously (Hague et al, 1993). Unfixed cells were stained with $5 \mu \mathrm{g} \mathrm{ml}^{-1}$ acridine orange in PBS for $10 \mathrm{~min}$ and were then viewed by fluorescence microscopy. For each experiment, the cells shed into the medium were confirmed to be morphologically apoptotic with condensed chromatin. At least 150 cells were scored per sample. To further demonstrate that TRAIL induced apoptotic death, adherent and floating cells were examined separately for DNA laddering as described previously (Hague et al, 1993). Cleavage of PARP was detected by Western blot analysis.

\section{SDS-PAGE-Western blotting}

Western blotting was carried out used standard techniques and antibody binding was detected using an enhanced chemiluminescence (ECL) detection kit (Amersham, Buckinghamshire, UK) following the manufacturer's protocol. To detect BID, two antibodies were used: a polyclonal BID antibody $(1: 200)$ kindly provided by Dr Xiadong Wang (Howard Hughes Medical Institute, Texas) and a polyclonal BID antibody (AF860) $(1: 1000)$ from R\&D systems. c-FLIP rabbit polyclonal antibody was a gift from Dr D Nicholson (Merck Frosst, Canada) and was used at 1:1000. Results were confirmed using a mouse monoclonal antibody, NF-6 (Alexis Corporation) at $1: 1000$. XIAP was detected with a mouse monoclonal antibody used at 1:500 (BD Transduction Laboratories). A mouse monoclonal $\alpha$-tubulin antibody (Sigma, Poole, Dorset, UK) or a mouse monoclonal $\alpha$-GAPDH antibody (Advanced Immunochemical Inc., CA, USA) was used to assess equal loading of the gels, both at $1: 2000$. Secondary antibodies were anti-mouse or anti-rabbit horseradish peroxidase-conjugated antibodies (Sigma). 
Flow cytometric analysis of cell surface death receptor expression

TRAIL-R1, -R2, -R3 and -R4 receptor antibodies (clones M272, M413, M430 and M444, respectively) were kind gifts from Immunex Corp. (Seattle, WA, USA) and have been described previously (Griffith et al, 1999). These antibodies have been validated for flow cytometric measurement of surface TRAIL expression (Zhang et al, 2000; MacFarlane et al, 2002). A total of $10^{6}$ trypsinised colon cells (live) were incubated in blocking buffer (PBS containing $10 \%$ normal goat serum) for $30 \mathrm{~min}$ on ice to block nonspecific binding. They were then incubated for $1 \mathrm{~h}$ with anti-TRAIL receptor antibodies (diluted 1:50) at $4{ }^{\circ} \mathrm{C}$. After two washes in PBS and centrifugation for $5 \mathrm{~min}$ at $400 \mathrm{~g}$, the cells were resuspended in blocking buffer containing goat anti-mouse FITCconjugated antibody $\left(\mathrm{F}(\mathrm{ab})_{2}\right.$ fragment) (DAKO) (1:20 dilution) and incubated for $1 \mathrm{~h}$ at $4{ }^{\circ} \mathrm{C}$. The cells were then washed twice in cold PBS prior to analysis by flow cytometry (FACScan, Becton Dickinson). Dead cells were excluded by costaining the cells with propidium iodide. The propidium iodide-positive cells could then be gated out.

\section{Statistical analysis}

The response of adenomas and carcinomas was compared by a two-way analysis of variance of TRAIL-induced apoptosis (malignant potential $\times$ TRAIL concentration). For the comparison of TRAIL sensitivity between the parental adenoma cell line AA/C1 and the transformed adenoma cell line AA/C1/SB/10, a two-way analysis of variance was conducted (cell line $\times$ TRAIL concentration). All analyses were conducted using SPSS 10 for Windows software.

\section{RESULTS}

Colorectal cancer cells are more sensitive to TRAILinduced apoptosis than premalignant adenoma cells

In this study, we addressed whether there is differential sensitivity to TRAIL-induced apoptosis between malignant and premalignant colorectal epithelial cells. Initially, the apoptotic response of four premalignant, nontumorigenic adenoma cell lines (RG/C2, RR/C1, $\mathrm{AN} / \mathrm{C} 1$ and $\mathrm{AA} / \mathrm{C} 1$ ) was compared with that of three carcinoma cell lines (HT29, SW620 and KS) by conducting dose-response experiments for each cell line. In order to determine the extent of resistance of the adenoma cells, relatively high concentrations of TRAIL were used $\left(0.25-1 \mu \mathrm{g} \mathrm{ml}^{-1}\right)$. As in our previous studies quantifying apoptosis in colon cells, we used cell shedding as an assessment of the extent of apoptosis (Hague et al, 1993). The cells shed into the medium in response to TRAIL treatment were confirmed to be apoptotic by acridine orange staining and examination of the floating cells by fluorescent microscopy for condensed chromatin, PARP cleavage to its $85 \mathrm{kDa}$ form and DNA laddering (data not shown). Treatment with TRAIL did not induce necrosis in any of the cell lines even at concentrations up to $2 \mu \mathrm{g} \mathrm{ml}^{-1}$. Measurements of the extent of apoptotic cell shedding after a $16 \mathrm{~h}$ treatment demonstrated that, although TRAIL induced apoptosis in the adenoma cell cultures, the carcinoma cell lines were markedly more sensitive to TRAIL than the adenoma cell lines (Figure 1). When extensive shedding was obtained over the $16 \mathrm{~h}$ treatment period, this was reflected in reduced adherent cell yields (data not shown). The three carcinoma cell lines were markedly more sensitive than the four adenoma cell lines, a difference that was highly statistically significant $(P<0.001)$.

To confirm that TRAIL-mediated apoptosis was due to receptor ligation and not due to nonspecific toxicity of TRAIL, a TRAIL-R2Fc chimeric protein, comprised of the TRAIL-R2 extracellular domain fused to human $\mathrm{IgG}_{1} \mathrm{Fc}$, was used as a soluble receptor

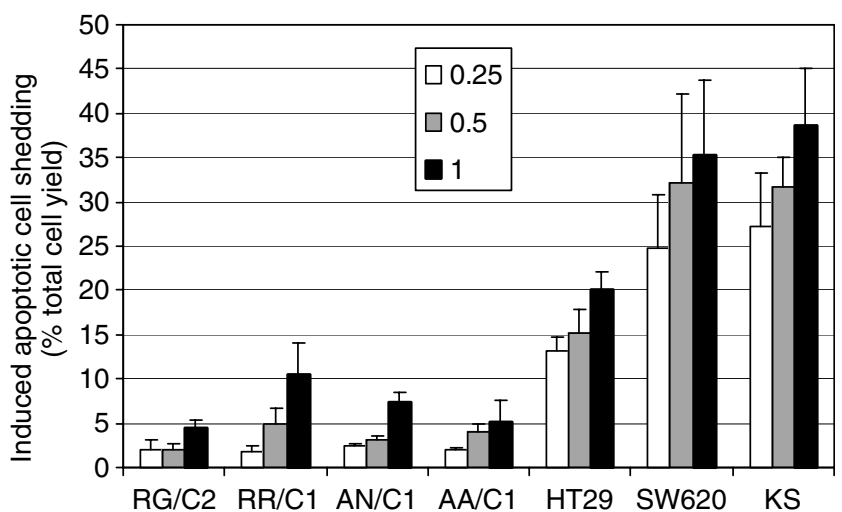

Figure I Induction of apoptotic cell shedding by TRAIL in four colorectal adenoma cell lines (RG/C2, RR/CI, AN/Cl and $\mathrm{AA} / \mathrm{Cl}$ ) and in three carcinoma cell lines (HT29, SW620 and KS). Cells were treated in exponential growth with either vehicle only or $0.25,0.5$ or $1.0 \mu \mathrm{g} \mathrm{ml}^{-1}$ TRAIL for $16 \mathrm{~h}$. The floating cells and adherent cells were counted separately. Floating cells were confirmed as apoptotic by acridine orange staining for each experiment. The extent of apoptosis was calculated as the proportion of the total cells in the flask that were floating in the medium For each experiment, TRAIL-induced apoptosis is shown as the percentage of apoptotic cells shed into the medium over and above that in the contro cultures. Data are means \pm s.e.m. of at least three experiments conducted either in duplicate or triplicate. The percentages of floating apoptotic cells in the control cultures were as follows: $12.12 \%$ for RG/C2, 3.66\% for RR/CI, I.85\% for $\mathrm{AN} / \mathrm{Cl}, 3.55 \%$ for $\mathrm{AA} / \mathrm{Cl}, 1.01 \%$ for HT29, 3.56\% for SW620 and $3.47 \%$ for $\mathrm{KS}$. The mean induced apoptotic cell shedding was compared between adenoma-derived cell lines and carcinoma-derived cell lines using a two-way analysis of variance. The difference was highly statistically significant $(P<0.00 \mathrm{I})$.

and blocking reagent. TRAIL-R2-Fc completely blocked TRAILinduced apoptotic cell shedding in the carcinoma cell line HT29, confirming that death receptor-mediated apoptosis was responsible for the cell shedding induced by TRAIL treatment (Figure 2A). Consistent with this, TRAIL treatment resulted in activation of caspase-8, with cleavage of the proform of $55 \mathrm{kDa}$ to 43,41 and $18 \mathrm{kDa}$ fragments (Figure $2 \mathrm{~B}$ ) together with cleavage of the $26 \mathrm{kDa}$ proform of BID to yield its $15 \mathrm{kDa}$ fragment (Figure 2C). Cleavage of caspase- 8 and BID was accompanied by reduced levels of the full-length forms (Figure 2B and C).

The in vitro-transformed adenoma cell line AA/C1/SB/10 is more sensitive to TRAIL-induced apoptosis than the parental adenoma cell line AA/C1

Since adenoma cells appeared to be more resistant to TRAIL than carcinoma cells, experiments were conducted to determine more directly whether TRAIL sensitivity increased in association with malignant progression by comparing the sensitivity of $\mathrm{AA} / \mathrm{C} 1$, an anchorage-dependent, nontumorigenic, adenoma-derived cell line, and $\mathrm{AA} / \mathrm{C} 1 / \mathrm{SB} / 10$, an anchorage-independent, tumorigenic derivative of the AA/C1 cell line (Williams et al, 1990). In these experiments, cell shedding was confirmed to be due to apoptosis by acridine orange staining for apoptotic morphology and by detection of PARP cleavage (data not shown). Although the transformed $\mathrm{AA} / \mathrm{C} 1 / \mathrm{SB} / 10$ cell line had lower levels of spontaneous apoptosis than the parental $\mathrm{AA} / \mathrm{C} 1$ cell line, dose-response experiments demonstrated that $\mathrm{AA} / \mathrm{C} 1 / \mathrm{SB} / 10$ was more sensitive to TRAIL-induced apoptosis than AA/C1 $(P<0.001)$ (Figure 3 ). The AA/C1 cells remained relatively resistant with increasing concentrations of TRAIL $\left(0.25,0.5\right.$ and $\left.1 \mu \mathrm{g} \mathrm{ml}^{-1}\right)$. Even $2 \mu \mathrm{g} \mathrm{ml}^{-1}$ TRAIL did not induce as much apoptotic cell shedding in AA/C1 as that induced by $0.25 \mu \mathrm{g} \mathrm{ml}^{-1}$ in $\mathrm{AA} / \mathrm{C} 1 / \mathrm{SB} / 10$ (data not shown). Therefore, the differential sensitivity between the two cell lines was 
A

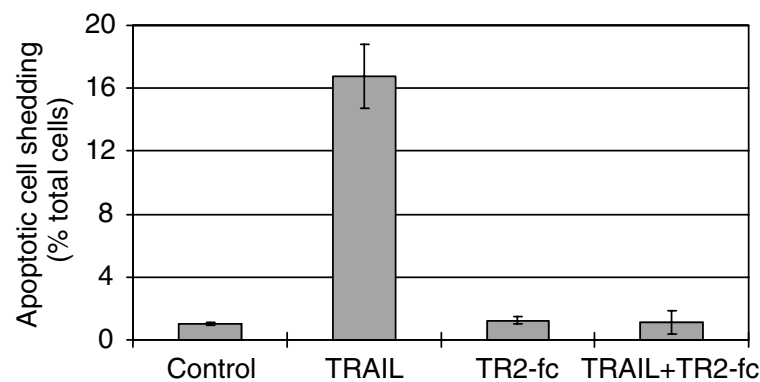

B Markers
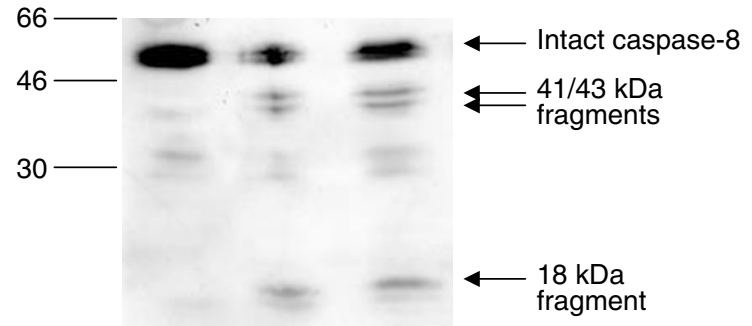

14.3

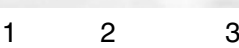

C

\section{Markers}

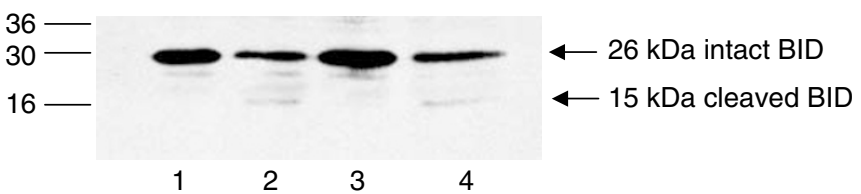

Figure 2 (A) Apoptosis induced by TRAlL is receptor-mediated and involves cleavage of caspase- 8 and BID. Apoptosis induced by TRAIL in the HT29 cell line is blocked using TRAIL R2-Fc chimeric protein (R and D systems, Abingdon, UK) to compete with cellular TRAIL receptors for the death ligand. Apoptotic cell shedding induced by $0.25 \mu \mathrm{g} \mathrm{m}{ }^{-1}$ TRAlL was completely blocked by $300 \mu \mathrm{g} \mathrm{ml}{ }^{-1}$ TRAIL-R2-Fc. (B) Caspase- 8 is cleaved in HT29 cells in response to TRAIL treatment $(16 \mathrm{~h})$. Lane I: adherent control cells; lane 2: adherent cells treated with $0.125 \mu \mathrm{g} \mathrm{ml} l^{-1}$ TRAIL; lane 3: adherent cells treated with $0.25 \mu \mathrm{g} / \mathrm{ml}$ TRAIL. (C) BID is cleaved in HT29 cells in response to $16 \mathrm{~h}$ TRAIL treatment. Lane I: control adherent cells; lane 2: TRAIL-treated adherent cells $\left(0.25 \mu \mathrm{gml} l^{-1}\right)$; lane 3: control adherent and floating cells pooled; lane 4: TRAlL-treated adherent and floating cells pooled.

evident even at high TRAIL concentrations. Furthermore, the differential sensitivity was maintained even after $96 \mathrm{~h}$ exposure to TRAIL (data not shown). It can be concluded that AA/C1 became more sensitive to TRAIL-induced apoptosis during malignant transformation in vitro.

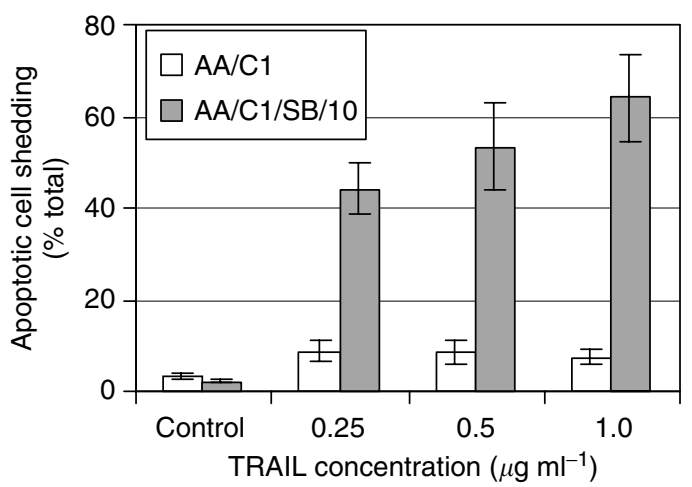

Figure 3 The in vitro-transformed, tumorigenic $\mathrm{AA} / \mathrm{CI} / \mathrm{SB} / \mathrm{I} 0$ cell line is more sensitive to TRAlL-induced apoptosis than the adenoma cell line AAV $\mathrm{Cl}$ from which it was derived. Dose response of the adenoma cell line AAV $\mathrm{Cl}$ and the in vitro-transformed adenoma cell line $\mathrm{AA} / \mathrm{CI} / \mathrm{SB} / \mathrm{IO}$ showing the extent of apoptotic cell shedding after a $16 \mathrm{~h}$ treatment with $0.25,0.5$ and $\mid \mu \mathrm{g} \mathrm{ml}^{-1}$ TRAIL. Results shown are means \pm s.e.m. of three experiments performed in triplicate. Comparing the percentage of apoptotic cell shedding between $\mathrm{AA} / \mathrm{Cl}$ and $\mathrm{AA} / \mathrm{Cl} / \mathrm{SB} / \mathrm{IO}$ by a two-way analysis of variance revealed a significantly greater extent of apoptosis in $\mathrm{AA} / \mathrm{CI} / \mathrm{SB} / \mathrm{IO}(\mathrm{P}<0.00 \mathrm{I})$.

Cell surface receptor expression profiles of adenoma and carcinoma cells cannot account for their differential sensitivity to TRAIL

Since it has been reported that there are no differences in total TRAIL receptor expression between colorectal adenomas and carcinomas (Koornstra et al, 2003), we addressed whether the differential sensitivity between nonmalignant and malignant colonic epithelial cells could be explained by relative cell surface expression of TRAIL receptors. To do this, flow cytometric analysis of antibody-labelled nonfixed cells was performed. The antibodies used to detect TRAIL receptors have been well characterised for efficient receptor binding by Griffith et al (1999) and for detection of cell surface TRAIL receptors by flow cytometry (Zhang et al, 2000; MacFarlane et al, 2002). TRAIL-R1 levels were low and similar in adenoma and carcinoma cell lines (Table 1). TRAIL-R2 was expressed in all of the eight cell lines and was the most abundant of the four receptors. AA/C1, which was relatively resistant to TRAIL, had the highest levels of TRAIL-R2, whereas KS, which was sensitive to TRAIL-induced apoptosis, had low levels. TRAIL-R3 was expressed in the adenoma cell lines AN/C1 and $\mathrm{AA} / \mathrm{C} 1$, and in the transformed adenoma cell line $\mathrm{AA} / \mathrm{C} 1 / \mathrm{SB} /$ 10 , but interestingly, the other five colonic tumour cell lines did not express cell surface TRAIL-R3. Similarly, only three cell lines expressed the TRAIL-R4 receptor (at low levels): the carcinoma cell line HT29, the adenoma cell line AN/C1 and the transformed

Table I Flow cytometric analysis of TRAIL receptor expression

\begin{tabular}{|c|c|c|c|c|c|c|c|c|}
\hline & \multicolumn{4}{|c|}{ Adenoma cell lines } & \multirow{2}{*}{$\begin{array}{c}\text { Transformed adenoma } \\
\text { AA/CI/SB/10 }\end{array}$} & \multicolumn{3}{|c|}{ Carcinoma cell lines } \\
\hline & $\mathbf{R G} / \mathbf{C 2}$ & $\mathbf{R R} / \mathbf{C l}$ & AN/CI & AA/CI & & HT29 & SW620 & KS \\
\hline $\begin{array}{l}\text { TRAIL-RI } \\
\text { TRAIL-R2 } \\
\text { TRAIL-R3 } \\
\text { TRAIL-R4 }\end{array}$ & $\begin{array}{r}5.50 \\
13.75 \\
4.10 \\
4.31\end{array}$ & $\begin{array}{r}7.49 \\
25.69 \\
5.90 \\
5.80\end{array}$ & $\begin{array}{r}8.70 \\
27.14 \\
9.39 \\
8.02\end{array}$ & $\begin{array}{r}7.55 \\
98.18 \\
10.60 \\
6.67\end{array}$ & $\begin{array}{r}4.84 \\
27.97 \\
4.10 \\
5.54\end{array}$ & $\begin{array}{r}5.19 \\
17.01 \\
3.92 \\
4.38\end{array}$ & $\begin{array}{r}5.84 \\
24.67 \\
3.91 \\
4.20\end{array}$ & $\begin{array}{l}2.81 \\
4.52 \\
2.49 \\
2.48\end{array}$ \\
\hline
\end{tabular}

Values are the mean fluorescent intensity of live (propidium iodide-excluding) cells stained with monoclonal antibodies and detected using an FITC-conjugated mouse secondary antibody. ${ }^{a}$ Cells incubated without primary or secondary antibody. ${ }^{b}$ Cells incubated with secondary antibody only. 
adenoma cell line AA/C1/SB/10. The expression pattern of the TRAIL receptors did not correlate with sensitivity to TRAIL or the malignant potential of the cell lines. Similarly, the receptor profiles of the AA/C1 cell line and the transformed adenoma cell line AA/ $\mathrm{C} 1 / \mathrm{SB} / 10$ did not explain why the transformed derivative was more sensitive to TRAIL-induced apoptosis (Figure 4 and Table 1).

\section{The relative resistance of the adenoma cell lines to TRAIL-induced apoptosis cannot be accounted for by higher expression of XIAP or c-FLIP}

Given the lack of correlation between malignant potential and TRAIL receptor expression, we further investigated the relative resistance of adenoma cell lines to TRAIL by examining intracellular components of the death receptor signalling pathway that have previously been shown to modulate TRAIL sensitivity. c-FLIP, an inhibitor of caspase- 8 activation, and XIAP, an inhibitor of active caspases- 3 and -9 , were expressed in all of the cell lines. c-FLIP ${ }_{\mathrm{L}}$ levels were markedly higher in the transformed adenoma cell line $\mathrm{AA} / \mathrm{C} 1 / \mathrm{SB} / 10$ than in the parental adenoma cell line AA/C1 (Figure 5, top panel, compare lanes 4 and 5). Thus, c-FLIP levels
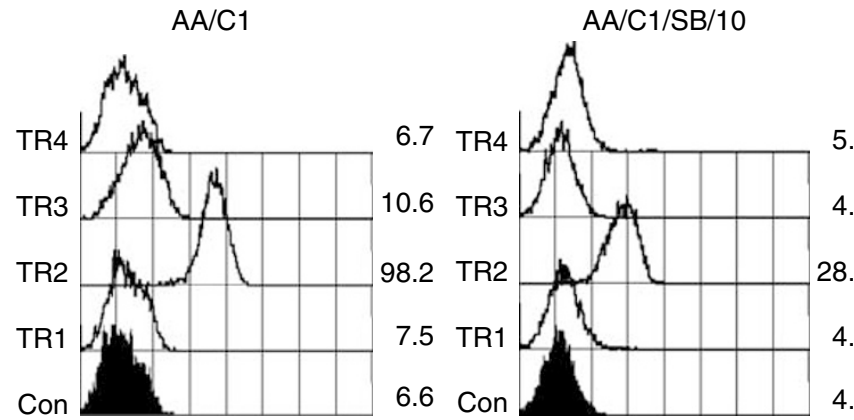

Figure 4 Cell surface receptor expression in the adenoma cell line AA/ $\mathrm{Cl}$ (premalignant) and the in vitro-transformed derivative $\mathrm{AA} / \mathrm{CI} / \mathrm{SB} / \mathrm{IO}$ (malignant). Cell surface expression of the four TRAIL receptors was detected by single-colour flow cytometric analysis of live (propidium iodide-excluding) cells stained with monoclonal antibodies and detected using a FITC-conjugated anti-mouse secondary antibody (See legend to Table I, values shown correspond to Mean Fluorescence Intensity). Control cells were incubated with secondary antibody only. The experiment was repeated with similar results.
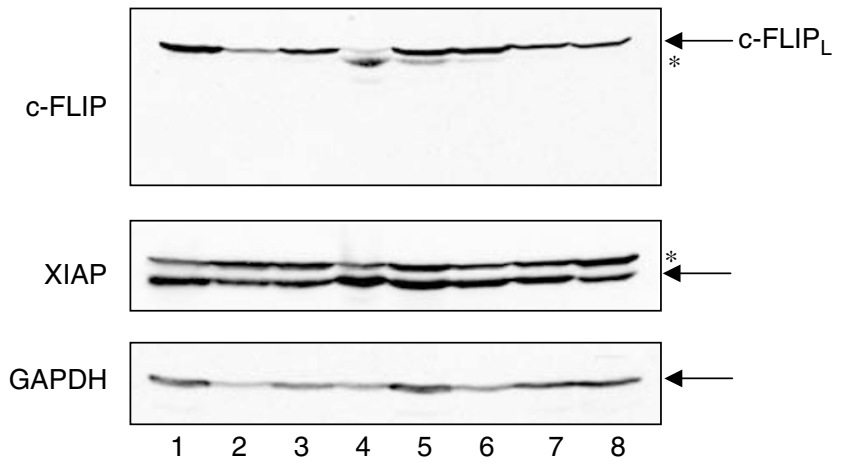

Figure 5 The relative resistance of the adenoma cell lines to TRAILinduced apoptosis cannot be accounted for by higher expression of XIAP or c-FLIP. c-FLIP and XIAP expression in the four adenoma cell lines, the transformed adenoma cell line and the three carcinoma cell lines is shown Lane I: RG/C2; lane 2: RR/CI; lane 3: AN/CI; lane 4: AA/Cl; lane 5: AA CI/SB/I 0; lane 6: HT29; lane 7: SW620; lane 8: KS. Bands corresponding to the full-length proteins are arrowed. The asterisks denote nonspecific bands. Since XIAP is of similar size to $\alpha$-tubulin, GAPDH was used as a loading control for this blot. did not appear to correlate with TRAIL sensitivity. Although cFLIP $_{S}$ serves to inhibit TRAIL-induced apoptosis in some cell types (Bin et al, 2002), none of the colorectal tumour cell lines expressed c-FLIP $_{S}$. XIAP levels also did not appear to correlate with TRAIL sensitivity. Although XIAP levels were slightly higher in the parental adenoma cell line $\mathrm{AA} / \mathrm{C} 1$ than in $\mathrm{AA} / \mathrm{C} 1 / \mathrm{SB} / 10$, the other cell lines had similar expression levels of XIAP (Figure 5, middle panel).

\section{DISCUSSION}

Interest in TRAIL as a potential chemotherapeutic agent stems from observations suggesting that it may selectively induce apoptosis in cancer cells while sparing normal cells. Increased sensitivity to TRAIL during carcinogenesis is not a feature of all tissues; for example, comparisons of the response of normal and malignant ovarian cells to TRAIL have shown normal cells to be sensitive to TRAIL whereas cells from different ovarian carcinomas varied in their responses (Lane et al, 2004). Normal colonocytes have previously been reported to be relatively resistant to TRAILinduced apoptosis compared to colorectal carcinoma cells: normal human colonic epithelial cells did not undergo apoptosis in response to $0.1 \mu \mathrm{g} \mathrm{ml}^{-1}$ TRAIL, but COLO205 colon carcinoma cells were sensitive to this concentration (Sträter et al, 2002b). Koornstra et al (2003) reported that colonic tumours overexpressed the TRAIL receptors TRAIL-R1 and TRAIL-R2 in vivo relative to normal mucosa, but that overall expression of TRAIL receptors was not significantly different between adenomas and carcinomas. On the basis of these observations, one might predict that the acquisition of TRAIL sensitivity would occur early in colorectal carcinogenesis and that adenoma cells would be as sensitive to TRAIL-induced apoptosis as carcinoma cells. However, it was not known whether there was a difference in TRAIL sensitivity between adenoma and carcinoma cells and whether TRAIL receptor expression on the cell surface, rather than intracellular receptor pools, would correlate with sensitivity to TRAIL-induced apoptosis. We addressed this hypothesis by comparing the extent of apoptosis induced by TRAIL in nonmalignant and malignant colorectal tumour cell lines. We initially questioned whether TRAIL was able to induce apoptosis of human colorectal adenoma cells, since this has not been reported before. The adenoma-derived cell lines did exhibit some apoptosis in response to TRAIL; however, all four adenoma cell lines, AA/C1, $\mathrm{AN} / \mathrm{C} 1, \mathrm{RR} / \mathrm{C} 1$ and RG/C2, were markedly more resistant than the three carcinoma cell lines HT29, SW620 and KS. The differential sensitivity between the adenoma and carcinoma cell lines was highly statistically significant $(P<0.001)$. Furthermore, we used an in vitro model of colorectal carcinogenesis to demonstrate that the adenoma cell line AA/C1 became more sensitive to TRAIL after in vitro transformation to a malignant phenotype $(P<0.001)$. Our studies provide direct evidence for increasing TRAIL sensitivity during colorectal carcinogenesis during the adenoma to carcinoma transition. They also show that the increased sensitivity to TRAIL can be recapitulated in vitro, and therefore in vivo selection pressures are not necessarily required for the acquisition of TRAIL sensitivity. The increased TRAIL sensitivity may relate to increasing growth rate or growth autonomy, or to the attainment of anchorage independence.

In normal colonic epithelium, apoptosis is primarily at the crypt lumen (Brodie et al, 2004), and for the most part at the top of the crypts (Hall et al, 1994). In early adenomas, there is apoptosis close to the basement membrane, particularly at crypt branching points (Brodie et al, 2004), whereas crypt lumen apoptosis is a feature of larger adenomas, high-grade dysplasia and adenocarcinomas. It is unknown to what extent TRAIL responsiveness contributes to the changing patterns of apoptosis in human colorectal tumours. However, the contribution of TRAIL-R2 to colorectal tumour 
growth and apoptosis sensitivity has recently been demonstrated by Wang and El-Deiry (2004) using stable human colon cancer cell lines in which the function of TRAIL-R2 was ablated using inducible RNA interference in a mouse xenograft model. Inducible silencing of TRAIL-R2 in vivo accelerated growth of bioluminescent tumour xenografts and conferred resistance to the chemotherapeutic agent 5-FU. Sträter et al (2002a) found that in normal colonic epithelium, TRAIL and TRAIL-R2 were expressed primarily in the surface epithelium, whereas TRAIL-R1 and TRAIL-R4 were detected all along the crypt axis. In adenomas, this expression pattern was mostly retained, although some adenomas also expressed abnormally high levels of TRAIL-R3. In carcinomas, the expression of TRAIL and TRAIL receptors was much more variable, but TRAIL-R1 expression was significantly associated with disease-free survival. Koornstra et al (2003) also reported overall expression of TRAIL receptors, which have a large cytoplasmic component, to be similar in adenoma and carcinoma cells; therefore, immunohistochemical studies have not revealed a mechanism for the differences in TRAIL sensitivity between the adenoma and carcinoma cells. We therefore examined the cell surface expression of the four TRAIL receptors by flow cytometry. The importance of examining cell surface expression of TRAIL receptors has been highlighted recently by Jin et al (2004), who showed that TRAIL-resistant variants of the colon carcinoma cell line SW480 had reduced cell surface expression of TRAIL-R1 compared to the parental cell line, although total protein expression remained unchanged. However, it is interesting that in our study the cell surface expression of the four TRAIL receptors did not correlate with the increased sensitivity to TRAIL that is associated with malignancy. Importantly, this indicates that the increased sensitivity to TRAIL may instead be due to alterations in intracellular signalling. In this regard, it is worth noting that we found no correlation between the expression of c-FLIP or XIAP, or of Bcl-2 family members Bcl-2, Bcl-xL, Bax or Bak to explain the differential sensitivity (data not shown). Furthermore, TRAIL-induced NF- $\kappa$ B activity did not correlate with

\section{REFERENCES}

Arai T, Akiyama Y, Okabe S, Saito K, Iwai T, Yuasa Y (1998) Genomic organization and mutation analyses of the DR5/TRAIL receptor 2 gene in colorectal carcinomas. Cancer Lett 133: 197-204

Ashkenazi A, Dixit VM (1998) Death receptors: signaling and modulation. Science 281: $1305-1308$

Ashkenazi A, Pai RC, Fong S, Leung S, Lawrence DA, Marsters S, Blackie C, Chang L, McMurtrey AE, Hebert A, DeForge L, Koumenis IL, Lewis D, Harris L, Bissiere J, Koeppen H, Shahrokh Z, Schwall RH (1999) Safety and antitumor activity of recombinant Apo2 ligand. J Clin Invest 104: $55-62$

Bin L, Xiaoyan L, Xu LG, Shu HB (2002) The short splice form of Casper/ cFLIP is a major inhibitor of TRAIL-induced apoptosis. FEBS Lett 510: $37-40$

Brodie CM, Crotty PL, Gaffney EF (2004) Morphologically distinct patterns of apoptosis correlate with size and high-grade dysplasia in colonic adenomas. Histopathology 44: 240-246

Chaudhary PM, Eby M, Jasmin A, Bookwalter A, Murray J, Hood L (1997) Death receptor 5, a new member of the TNFR family, and DR4 induce FADD-dependent apoptosis and activate the NF- $\kappa \mathrm{B}$ pathway. Immunity 7: $821-830$

Degli-Eposti MA, Dougall WC, Smolak PJ, Waugh JY, Smith CA, Goodwin RG (1997) The novel receptor TRAIL-R4 induces NF- $\kappa \mathrm{B}$ and protects against TRAIL-mediated apoptosis, yet retains an incomplete death domain. Immunity 7: 813-820

French LE, Tschopp J (1999) The TRAIL to selective tumor death. Nat Med 5: $146-147$

Fogh J, Trempe G (1975) New human tumour cell lines. In Human Tumour cells in vitro Fogh J (ed) pp 115-141. New York: Plenum Press malignant potential or sensitivity to TRAIL-induced apoptosis (data not shown).

In summary, using an in vitro model of colorectal tumour progression, we have demonstrated for the first time that colorectal adenoma cells are more resistant to TRAIL-induced apoptosis than carcinoma cells and that TRAIL sensitivity increases during the conversion of an adenoma cell line to a malignant phenotype. Importantly, since the adenoma cultures are grown under the same culture conditions as the carcinoma cultures, this cannot be attributed to differences in survival factors or medium composition. The results are important for the potential application of TRAIL as a treatment for colorectal cancer because of the current focus on the mechanisms of TRAIL resistance in colorectal tumours - it will be important to define the 'window' of TRAIL sensitivity. Although the mechanism for the differential sensitivity of benign and malignant cells to TRAIL remains elusive, our data indicate that death receptor expression alone cannot explain why cells become sensitive to TRAIL on acquisition of the malignant phenotype. Therefore, in addition to defining mechanisms by which resistant variants may subsequently arise after prolonged TRAIL treatment, further investigations are also needed to define the mechanisms by which colorectal carcinoma cells become sensitive to TRAIL and what selective advantage of tumour cells has given rise to this sensitivity. Together, these investigations will assist in the optimisation of TRAIL for therapeutic use.

\section{ACKNOWLEDGEMENTS}

We thank the Cancer Research UK, the Citrina Foundation and the MRC for funding. We are grateful to Immunex for the TRAIL antibodies, D Nicholson for the c-FLIP antibody and X Wang for the BID antibody. We also thank Roger T Snowden for his help with the flow cytometric analysis of TRAIL receptors and Ann C Williams for her helpful comments on the manuscript.

Gliniak B, Le T (1999) Tumor necrosis factor-related apoptosis-inducing ligand's antitumor activity in vivo is enhanced by the chemotherapeutic agent CPT-11. Cancer Res 59: 6153-6158

Green DR (1998) Death deceiver. Nature 396: 629-630

Griffith TS, Chin WA, Jackson GC, Lynch DH, Kubin MZ (1998) Intracellular regulation of TRAIL-induced apoptosis in human melanoma cells. I Immunol 161: 2833-2840

Griffith TS, Rauch CT, Smolak PJ, Waugh JY, Boiani N, Lynch DH, Smith CA, Goodwin RG, Kubin MZ (1999) Functional analysis of TRAIL receptors using monoclonal antibodies. J Immunol 162: 2597-2605

Hague A, Díaz GD, Hicks DJ, Krajewski S, Reed JC, Paraskeva C (1997) Bcl-2 and Bak may play a pivotal role in sodium butyrate-induced apoptosis in colonic epithelial cells, however overexpression of Bcl-2 does not protect against Bak mediated apoptosis. Int J Cancer 72: 898-905

Hague A, Manning AM, Hanlon KA, Huschtscha LI, Hart D, Paraskeva C (1993) Sodium butyrate induces apoptosis in human colonic tumour cell lines in a p53-independent pathway: implications for the possible role of dietary fibre in the prevention of large-bowel cancer. Int J Cancer 55: 498-505

Hall PA, Coates PJ, Ansari B, Hopwood D (1994) Regulation of cell number in the mammalian gastrointestinal tract: the importance of apoptosis. J Cell Sci 107: 3569 - 3577

Jin Z, McDonald III ER, Dicker DT, El-Diery WS (2004) Deficient tumor necrosis factor-related apoptosis-inducing ligand (TRAIL) death receptor transport to the cell surface in human colon cancer cells selected for resistance to TRAIL-induced apoptosis. J Biol Chem 279: 35829-35839

Kim K, Fisher MJ, Xu S-Q, El-Deiry WS (2000) Molecular determinants of response to TRAIL in killing of normal and cancer cells. Clin Cancer Res 6: $335-346$ 
Koornstra JJ, de Jong S, Rijcken F, van der Sluis T, Jalving M, Hollema H, de Vries E, Kleibeuker J (2001) Differential expression of Trail receptor DR4 in normal colonic mucosa, colorectal adenomas and colorectal cancer. Proc Am Asso Cancer Res 42: 612-613

Koornstra JJ, Kleibeuker JH, van Geelen CM, Rijcken FE, Hollema $\mathrm{H}$, de Vries EG, de Jong S (2003) Expression of TRAIL (TNF-related apoptosis-inducing ligand) and its receptors in normal colonic mucosa, adenomas, and carcinomas. J Pathol 200: 327-335

Lacour S, Hammann A, Wotawa A, Corcos L, Solary E, Dímanche-Boítrel MT (2001) Anticancer agents sensitize tumor cells to tumor necrosis factor-related apoptosis-inducing ligand-mediated caspase-8 activation and apoptosis. Cancer Res 61: 1645-1651

Lacour S, Micheau O, Hammann A, Drouineaud V, Tschopp J, Solary E, Dimanche-Boitrel MT (2003) Chemotherapy enhances TNF-related apoptosis-inducing ligand DISC assembly in HT29 human colon cancer cells. Oncogene 22: $1807-1816$

Lane D, Cartier A, L'Esperance S, Cote M, Rancourt C, Piche A (2004) Differential induction of apoptosis by tumor necrosis factor-related apoptosis-inducing ligand in human ovarian carcinoma cells. Gyneco Oncol 93: 594-604

Larribere L, Khaled M, Tartare-Deckert S, Busca R, Luciano F, Bille K, Valony G, Eychene A, Auberger P, Ortonne JP, Bollotti R, Bertolotto C (2004) PI3K mediates protection against TRAIL-induced apoptosis in primary melanocytes. Cell Death Differ 11: 1084-1091

Lazebnik YA, Kaufmann SH, Desnoyers S, Poirier GG, Earnshaw WC (1994) Cleavage of poly(ADP-ribose) polymerase by a proteinase with properties like ICE. Nature 371: 346-347

Lee YJ, Lee KH, Kim HR, Jessup JM, Seol DW, Kim TH, Billiar TR, Song YK (2001) Sodium nitroprusside enhances TRAIL-induced apoptosis via a mitochondria-dependent pathway in human colorectal carcinoma CX-1 cells. Oncogene 20: $1476-1485$

Leibovitz A, Stinson JC, McCombs WB, McCoy CE, Mazur KC, Mabry ND (1976) Classification of human colorectal adenocarcinoma cell lines. Cancer Res 36: $4562-4569$

MacFarlane M, Ahmad M, Srinivasula SM, Fernandes-Alnemri T, Cohen GM, Alnemri ES (1997) Identification and molecular cloning of two novel receptors for the cytotoxic ligand TRAIL. J Biol Chem 272: 25417-25420

MacFarlane M, Cohen GM, Dickens M (2000b) JNK (c-Jun N-terminal kinase) and p38 activation in receptor-mediated and chemically-induced apoptosis of T-cells: differential requirements for caspase activation. Biochem J 348: 93 - 101

MacFarlane M, Harper N, Snowden RT, Dyer MJS, Barnett GA, Pringle JH, Merrison W, Bratton SB, Cohen GM (2002) Mechanisms of resistance to TRAIL-induced apoptosis in primary B cell CLL. Oncogene 21: $6809-6818$

MacFarlane M, Merrison W, Dinsdale D, Cohen GM (2000a) Active caspases and cleaved cytokeratins are sequestered into cytoplasmic inclusions in TRAIL-induced apoptosis. J Cell Biol 148: 1239-1254

Mühlenbeck F, Haas E, Schwenzer R, Schubert G, Grell M, Smith C, Scheurich P, Wajant H (1998) TRAIL/Apo2L activates c-Jun $\mathrm{NH}_{2-}$ terminal kinase via caspase-dependent and caspase-independent pathways. J Biol Chem 273: $33091-33098$
Paraskeva C, Buckle BG, Sheer D, Wigley CB (1984) Isolation and characterisation of colorectal epithelial cell lines at different stages in malignant transformation form familial polyposis coli patients. Int J Cancer 41: $908-912$

Paraskeva C, Finerty S, Mountford RA, Powell SC (1989) Specific cytogenetic abnormalities in two new human colorectal adenomaderived epithelial cell lines. Cancer Res 49: $1282-1286$

Pitti RM, Marsters SA, Ruppert S, Donahue CJ, Moore A, Ashkenazi A (1996) Induction of apoptosis by Apo-2 ligand, a new member of the tumor necrosis factor cytokine family. J Biol Chem 271: 12687-12690

Ravi R, Bedi GC, Engstrom LW, Zeng Q, Mookerjee B, Gélinas C, Fuchs EJ, Bedi A (2001) Regulation of death receptor expression and TRAIL/ Apo2L-induced apoptosis by NF- $\kappa$ B. Nat Cell Biol 3: 409-416

Schneider P, Thome M, Burns K, Bodmer J-L, Hofmann K, Kataoka T, Holler N, Tschopp J (1997) TRAIL receptors 1 (DR4) and 2 (DR5) signal FADD-dependent apoptosis and activate NF- $\kappa$ B. Immunity 7: 831-836

Sheikh MS, Huang Y, Fernandez-Salas EA, El-Diery WS, Friess H, Amundson S, Yin J, Meltzer SJ, Hobrook NJ, Fornace AJ (1999) The antiapoptotic decoy receptor TRID/TRAIL-R3 is a p53-regulated DNA damage-inducible gene that is overexpressed in primary tumors of the gastrointestinal tract. Oncogene 18: 4153-4159

Shimoyama S, Mochizuki Y, Kusada O, Kaminishi M (2002) Supra-additive antitumor activity of 5FU with tumor necrosis factor-related apoptosisinducing ligand on gastric and colon cancers in vitro. Int J Oncol 21: $643-648$

Sträter J, Hinz U, Walczak H, Mechtersheimer G, Koretz K, Herfarth C, Möller P, Lehnert T (2002a) Expression of TRAIL and TRAIL receptors in colon carcinoma: TRAIL-R1 is an independent prognostic parameter. Clin Cancer Res 8: $3734-3740$

Sträter J, Walczak H, Pukrop T, Von Müller L, Hasel C, Kornmann M, Mertens T, Möller P (2002b) TRAIL and its receptors in the colonic epithelium: a putative role in the defence of viral infections. Gastroenterology 122: 659-666

Wang S, El-Deiry WS (2003) TRAIL and apoptosis induction by TNF-family death receptors. Oncogene 22: $8628-8633$

Wang S, El-Deiry WS (2004) Inducible silencing of KILLER/DR5 in vivo promotes bioluminescent colon tumor xenograft growth and confers resistance to chemotherapeutic agent 5-fluorouracil. Cancer Res 64: $6666-6672$

Wiley SR, Schooley K, Smolak PJ, Din WS, Huang CP, Nicholl JK, Sutherland GR, Smith TD, Rauch C, Smith CA, Goodwin RG (1995) Identification and characterization of a new member of the TNF family that induces apoptosis. Immunity 3: 673-682

Williams AC, Harper SA, Marshall CJ, Gill RW, Mountford RA, Paraskeva C (1992) Specific cytogenetic abnormalilies and k-ras mutation in two new human colorectal-adenoma-derived cell lines. Int J Cancer 52: 758 - 790

Williams AC, Harper SJ, Paraskeva C (1990) Neoplastic transformation of a human colonic epithelial cell line: in vitro evidence for the adenoma to carcinoma sequence. Cancer Res 50: 4724-4730

Zhang XD, Franco AV, Nguyen T, Gray CP, Hersey P (2000) Differential localization and regulation of death and decoy receptors for TNF-related apoptosis-inducing ligand (TRAIL) in human melanoma cells. J Immunol 164: $3961-3970$ 